\title{
Prenatal nutritional influences on obesity risk in offspring
}

\author{
This article was published in the following Dove Press journal: \\ Nutrition and Dietary Supplements \\ 9 December 2010 \\ Number of times this article has been viewed
}

\section{Mark H Vickers \\ Deborah M Sloboda \\ Liggins Institute and the National Research Centre for Growth and Development, University of Auckland. Auckland, New Zealand}

\begin{abstract}
The incidence of obesity and overweight has almost doubled in Western societies over the last 2 decades, a trend mirrored in developing nations transitioning to first-world economies. Obesity is strongly associated with the comorbidities of type 2 diabetes, hypertension, and heart disease and represents an enormous burden to health care systems. Of even more concern is the increase of around $40 \%$ in the prevalence of childhood obesity and type 2 diabetes over the last 20 years. Metabolic disease results from complex interactions of many factors, including genetic, physiologic, behavioral, and environmental influences. The recent rate at which these diseases have increased suggests that environmental, eg, epigenetic, and behavioral influences, rather than genetic causes, are fuelling the present epidemic. In this context, the developmental origins of health and disease hypothesis has highlighted the link between periconceptual, fetal, and early infant phases of life and the subsequent development of adult obesity and related metabolic disorders. Both maternal undernutrition (global and targeted) and maternal obesity elicit an obese offspring phenotype. This review will examine the role of altered maternal nutrition on obesity risk in offspring, the interactions with the postnatal nutritional environment, the possible strategies for intervention, and the role of epigenetics in the disease process.
\end{abstract}

Keywords: developmental programming, obesity, metabolic syndrome, type 2 diabetes, developmental plasticity, critical windows

\section{Introduction}

Obesity is a serious health issue in the developed world and is becoming an increasing problem in those societies transitioning to first-world economies and lifestyles. It is a widely held view that the development of an obesogenic environment, due to ease of access to highly calorific food and reduced energy expenditure in work and leisure activities, is the primary cause of obesity in the general population. The globalization of agriculture and food processing has changed the food availability worldwide: the last 30 years have seen a 10-fold increase in the number of people with access to high-caloric diets. ${ }^{1,2}$ Together with reductions in the physical demands of work and increased mechanization, which have increased the propensity to a sedentary lifestyle, ${ }^{2}$ these changes have brought about a significant increase in the global incidence of obesity.

Multiple systems regulate energy homeostasis, and there is strong evidence for a genetic component to human obesity with the identification of a number of associated genes. ${ }^{3}$ However, genetics alone cannot account for the dramatic and rapid increase
Correspondence: Deborah Sloboda

Liggins Institute and the National

Research Centre for Growth

and Development, University

of Auckland, 2-6 Park Ave, Grafton,

1024 Auckland, New Zealand

Tel +6499233061

Fax +6493737497

Email d.sloboda@auckland.ac.nz 
in the prevalence of obesity in recent years. In this regard, epidemiological and experimental studies have highlighted a strong relationship between critical periods of development (conception, fetal, and early infant phases of life) and the subsequent development of adult obesity. ${ }^{4-6}$ There is now considerable epidemiological and experimental evidence indicating that environmental signals, including nutrition, operating during these critical windows affect subsequent development leading to pathophysiologies such as obesity and insulin resistance. These signals induce highly integrated responses in endocrine-related homeostasis, resulting in persistent changes to the developmental trajectory producing an altered adult phenotype. This phenomenon has been termed developmental programming, whereby early-life events trigger processes that prepare the individual for particular circumstances that are anticipated in the postnatal environment. ${ }^{7}$ Recently, Gluckman et al have proposed that developmental adaptations in response to environmental cues may not have immediate advantages for the individual's survival or fitness but may confer advantage at some later time. ${ }^{8}$ With this in mind, they proposed the predictive adaptive responses (PARs) framework that suggests that the fetus is able to predict its future environment from cues (nutritional and endocrine) provided by the mother and adjusts its developmental trajectory accordingly to best match its physiology to that environment. ${ }^{8,9}$ These responses do not confer immediate advantages for the fetus but provide a fitness advantage in later environments; the nature of which is predicted on the basis of the developmental conditions. As the phenotype develops, the nature of this advantage might alter at different points across the life course. ${ }^{9}$

But within this framework, PARs are adaptive only when the postdevelopmental environment is predicted correctly. If the postnatal environment differs dramatically from the prenatal one, there is a mismatch between these environments, and the organism has a phenotype that is not appropriate for the actual environment. Here, Gluckman et $\mathrm{al}^{10}$ hypothesize that disease risk is, therefore, a result of the degree of match or mismatch between the environment predicted by the organism during a critical period of developmental plasticity and the actual environment in which the organism lives during postnatal life.

In light of the rapid transitioning of some populations from a traditional society and culture to one of relative affluence where improvements in economic circumstances and nutrition have occurred relatively rapidly, there may occur a mismatch between the fetus' prediction of the postnatal environment and the subsequent reality, which may contribute to the increasing incidence of obesity and related metabolic disease in later life. ${ }^{10,11}$

\section{Epidemiological evidence}

There is no doubt that events occurring much earlier than childhood influence weight gain, adiposity, and metabolic function during childhood and beyond. ${ }^{12}$ Using epidemiological data, Barker et $\mathrm{al}^{13,14}$ were the first to describe a significant association between events occurring before birth and later-life disease risk, including hypertension and type 2 diabetes. Barker and colleagues demonstrated a relationship between low birth weight and an increased risk of subsequent hypertension, obesity, insulin resistance, and dyslipidemia. ${ }^{14-16}$ Within these observations, birth weight was used as a marker of early-life adversity, and we can now speculate that low birth weight may be used as a surrogate for developmental adaptations to prenatal cues. From these initial observations, the importance of maternal nutrition and, in particular, the effect of poor nutrition on birth weight (and indeed fetal adaptations) and the development of adult disease were addressed using historical cohorts that have undergone adversity (famine and war) during pregnancy. In particular, follow-up studies of survivors of the Dutch Winter Hunger ${ }^{4,17-19}$ have shown that the timing of adversity is a major determinant in phenotypic outcome. Famine exposure restricted to the last trimester of pregnancy and the first months of life, resulting in significantly lower obesity rates in adult offspring. ${ }^{4,17}$ However, if famine occurred in the first half of pregnancy, offspring were significantly more obese than nonexposed counterparts., ${ }^{417}$ The relationship between prenatal famine exposure and later-life obesity, however, does not demonstrate causation, and in fact, other reports of prenatal famine exposure have yielded contradictory results. Retrospective studies investigating offspring exposed to famine during the siege of Leningrad did not show any relationship between birth weight and adult metabolic sequelae. ${ }^{20}$ However, intriguingly, the disparity between the Dutch and the Leningrad studies may be explained using the PARs framework. After the Dutch Winter Hunger, nutrition was plentiful, and thus, in some cases, offspring would have been "starved" during fetal life and well nourished in postnatal life; this may represent a circumstance that Gluckman et al may consider a mismatch between the actual and the predicted environments. Conversely, in the Leningrad cohort, nutritional status was poor both before and after the period of famine, and thus one can speculate that any fetal adaptations may have been appropriate for predicted postnatal environment. 
Subsequent to papers by Barker et al ${ }^{13-15,21}$ describing associations between poor fetal growth and disease risk later in life, reports emerged that an interaction exists between embryonic or fetal and postnatal (childhood) events thereby amplifying disease risk. ${ }^{22}$ Human studies have provided evidence that restricted intrauterine growth followed by accelerated (or catch-up) growth may potentially be beneficial in the short-term but have adverse effects on subsequent metabolic function, ${ }^{23-25}$ blood pressure, and cardiovascular function. ${ }^{22,26}$ In historically undernourished but recently urbanized populations, such as in parts of India, where individuals of low birth weight are exposed to a high-fat Western diet, the incidence of obesity and type 2 diabetes is reaching epidemic proportions. ${ }^{27}$ Yajnik also showed that although Indian babies are born of low birth weight, they exhibit relatively increased visceral adiposity. ${ }^{27}$ This is consistent with other studies of small babies, showing disproportionate abdominal fat mass during adult life, despite a low body mass index (BMI). ${ }^{23,28}$ Interestingly, Parsons et $\mathrm{al}^{29}$ found that babies with a lower birth weight, who then exhibited catch-up growth to achieve a greater proportion of their adult height by age 7, had a risk of obesity comparable to that for babies with higher birth weights. Eriksson et al ${ }^{30}$ also demonstrated that ponderal index at birth was a reliable good predictor of later obesity and also found that an early adiposity rebound in babies born of low birth weight was associated with obesity in adult life.

\section{Maternal obesity and overweight}

Although prenatal growth restriction has clearly demonstrated influences on long-term adiposity, it is important to recognize that the relationship between birth weight and later-life pathophysiology is not linear. Large for gestational age babies are at risk of obesity and diabetes, associations that have been supported by a number of studies investigating the long-term effects of maternal hyperglycemia (diabetes or gestational diabetes). ${ }^{31-34}$ Although undernutrition remains a global crisis in many developing countries, worldwide, there is an increasing focus on the role of maternal obesity in determining health risk in offspring. Together with reductions in the physical demands of work and increased mechanization, ${ }^{2}$ these changes have brought about a significant increase in the global incidence of obesity. In developed countries, $15 \%-20 \%$ of women between the ages of 25 and 55 years are obese ${ }^{2}$ and, therefore, have increased risks of infertility and cardiovascular and metabolic disease. Now, more than ever, women are heavier, entering pregnancy overweight, and gaining excess weight during pregnancy. In developed societies, caloric and/or fat consumptions are generally excessive; therefore, unremarkably, maternal obesity is now a common pregnancy complication. ${ }^{35,36}$ Maternal obesity is associated with obstetric complications, including fetal and neonatal death and poor lactation outcomes, and is the most significant predictor of childhood obesity ${ }^{37}$ and metabolic syndrome in offspring. ${ }^{38}$ The underlying mechanisms are unclear, but reports suggest that adiposity and insulin resistance in children of obese mothers are already present during fetal life, and high maternal weight has been associated with abnormal fetoplacental function. ${ }^{39} \mathrm{In}$ a recent study, obese (BMI $>30 \mathrm{~kg}$ / $\left.\mathrm{m}^{2}\right)$ and lean $\left(\mathrm{BMI}<25 \mathrm{~kg} / \mathrm{m}^{2}\right)$ mothers with singleton pregnancies were evaluated at elective cesarean delivery for measure of maternal and fetal insulin resistance.$^{37}$ Fetuses of obese mothers had higher percentage of body fat, homeostasis model assessment of insulin resistance (Figure 1), and increased cord leptin than fetuses of lean women. These findings support the hypothesis that the metabolic compromise in offspring of obese mothers is present as early as fetal life.

Importantly, these effects may be self-perpetuating, as offspring of obese mothers are themselves prone to obesity, giving rise to transgenerational effects. ${ }^{40,41}$ Recent work demonstrates that children born to women who gained excessive weight in pregnancy had a greater fat mass during infancy compared with those with appropriate weight gain, and in this cohort, greater pregnancy weight gain was also weakly associated with fat mass at 6 years of age. ${ }^{42}$

\section{Evidence from animal models}

Animal models have been extensively used to study the basic physiological principles of developmental programming and

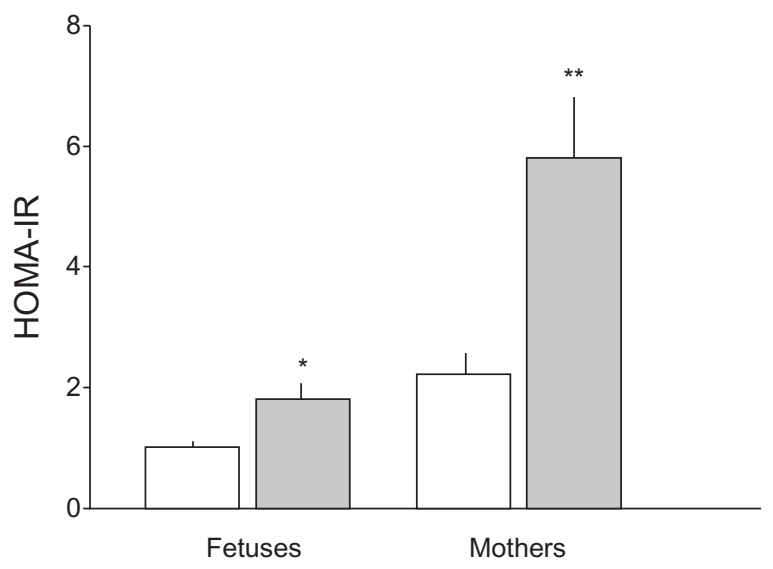

Figure I Homeostasis model assessment of insulin resistance (HOMA-IR) index in fetuses of lean (body mass index [BMl] $<25 \mathrm{~kg} / \mathrm{m}^{2}$, open bars) and obese (BMI $>30 \mathrm{~kg} / \mathrm{m}^{2}$, gray bars) mothers.

$* P<0.003$ and $* * P<0.001$ vs lean.

Note: From data of Catalano et al 2009.146 
are essential to the search of the mechanistic links between prenatal and postnatal influences and obesity risk in later life. Although epidemiological data suggest that developmental programming occurs within the normal range of birth size, ${ }^{43,44}$ most experimental work has tended to focus on significant restriction of fetal growth in the assumption that the nature of the insults that impair fetal growth are likely to be those that trigger developmental programming. Several approaches have been developed to induce early growth restriction in animals in an attempt to elucidate its relationship with adult-onset disease and provide a framework for investigating the underlying mechanisms. In the rat, obesity and metabolic disorders have been induced in offspring by maternal global undernutrition, ${ }^{45-50}$ a low-protein diet, ${ }^{51-53}$ maternal uterine artery ligation, ${ }^{54-56}$ maternal dexamethasone (DEX) treatment, ${ }^{57}$ maternal anemia, ${ }^{58}$ or prenatal cytokine exposure. ${ }^{59}$ In this context, it is important to consider that intrauterine growth restriction (IUGR) is not causal in developmental programming but is merely a surrogate for compromised fetal development and well-being.

\section{Maternal undernutrition}

The early work of Barker and colleagues highlighted the role of fetal nutrition as a primary factor involved in the developmental origins of adult disease. ${ }^{13,21,60}$ In the laboratory, fetal undernutrition can most commonly be achieved through maternal dietary restriction during pregnancy. At present, rodent models investigating the mechanistic links between maternal undernutrition and adult disease generally utilize 1 of 2 dietary protocols: global undernutrition or isocaloric low-protein diets. The maternal low-protein (MLP) diet during pregnancy and lactation is one of the most extensively utilized models of nutritional programming. ${ }^{61-66}$ This model involves ad libitum feeding to pregnant rats, a low-protein diet containing 5\%-8\% (w/w) protein (casein), generally a little under half the protein content but equivalent in energy of a control diet containing $18 \%-20 \%(\mathrm{w} / \mathrm{w})$ protein. ${ }^{67}$ Offspring from protein-restricted mothers are approximately 15\%-20\% lighter at birth. ${ }^{63}$ Maintenance of a MLP diet during lactation enhances this weight difference and permanently limits later growth. If MLP offspring are cross-fostered to mothers fed a control diet, they exhibit rapid catch-up growth. ${ }^{63}$ This catch-up growth appears to have a detrimental effect on life span, resulting in premature death, which is associated with accelerated loss of kidney telomeric DNA. ${ }^{68}$

Offspring of protein-restricted mothers demonstrate both central and peripheral insulin resistance, and alterations in insulin action and activity are tissue dependant. ${ }^{69}$
MLP offspring demonstrate altered insulin sensitivity in adipocytes, demonstrating changes in the activation of insulin receptor substrate-1 associated phosphoinositol 3-kinase (PI3K) activity. ${ }^{70}$ Alterations in expression of PI3K subunit suggests that adipocytes of protein-restricted offspring may be resistant to antilipolytic effects of insulin. ${ }^{70}$

Global undernutrition is another widely used approach to induce nutritional programming of obesity. Various models have been developed with different levels of undernutrition during different periods of pregnancy. Moderate nutritional restriction (to $70 \%$ of normal ad libitum intake) in the first 18 days of pregnancy in the rat resulted in offspring with significant IUGR that catch up in body weight to that of controls by postnatal day $20 .{ }^{71}$ These abnormalities increase with age and was most pronounced in male offspring.

We have developed rodent models of developmental programming using global maternal undernutrition throughout pregnancy. ${ }^{46,49,50}$ When dams are fed at $30 \%$ of ad libitum intake throughout pregnancy, ie, a severe level of undernutrition, birth weights and placental weights of offspring are $25 \%-30 \%$ lower than offspring of control fed mothers. These offspring display increased adiposity, hypertension, hyperinsulinemia, hyperleptinemia, reduced locomotor activity, leptin resistance, and hyperphagia in adult life. ${ }^{46,47,72}$ When the degree of undernutrition is more moderate, ie, $50 \%$ of ad libitum, offspring still display a significant level of obesity in postnatal life independent of postnatal diet (Figure 2A). Of note, if preweaning catch-up growth in offspring is prevented by maintaining the mothers on the restricted diet throughout lactation, offspring do not develop an obese phenotype (authors' unpublished observations). This is in agreement with outcomes from a previously published MLP model where continuation of the low-protein diet in lactation prevents the development of the metabolic phenotype in offspring, once again highlighting the adverse consequences of catch-up growth. ${ }^{73}$

Although maternal macronutrient malnutrition has been well studied, the role of maternal micronutrient restriction is less well known. From the limited data available, maternal micronutrient restriction has been directly associated with increased adiposity in offspring. Maternal dietary restriction in iron, zinc, calcium, and magnesium, individually or in combination, was found to result in increased percent body fat and some varying effects on insulin resistance in the offspring. ${ }^{74-77}$ Maternal chromium restriction significantly increased body weight and fat percentage, especially central adiposity, in both male and female rat offspring. ${ }^{78}$ Restricted vitamin intake during pregnancy has been shown to increase 
A

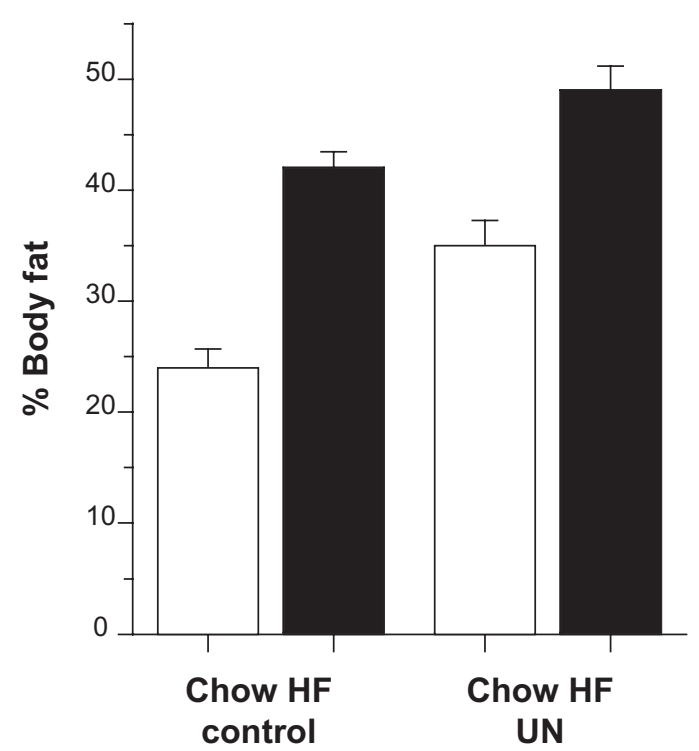

B

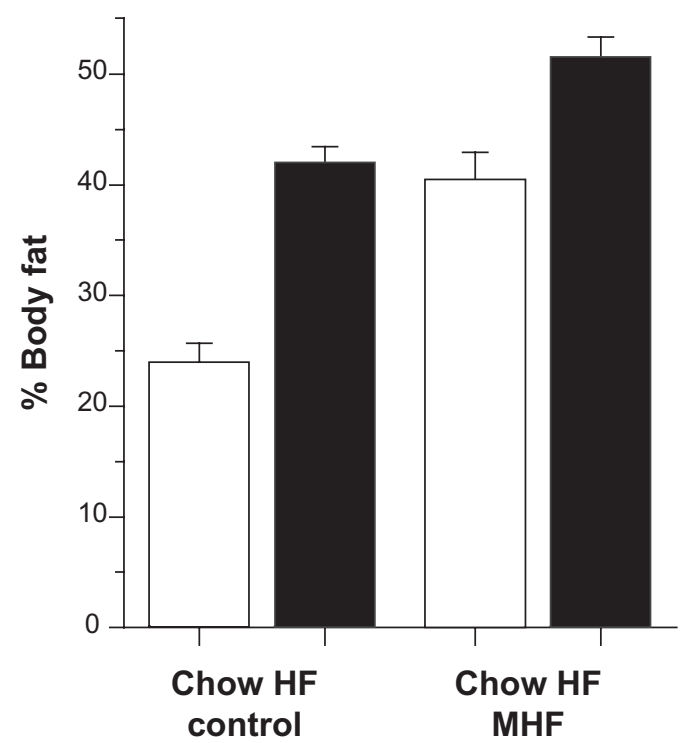

Figure 2 Increased adiposity (as quantified by dual-energy x-ray absorptiometry, DEXA) in male offspring fed either a chow or high fat (HF) diet post weaning of A) mothers undernourished (UN, $50 \%$ of ad libitum) throughout pregnancy or B) mothers fed a HF fat diet throughout pregnancy and lactation (MHF).

$P<0.05$ for the effect of maternal diet and postweaning HF diet.

Note: Data are means + SEM. $\mathrm{n}=$ minimum 8 per group.

the phenotypic expression of obesity and components of the metabolic syndrome in both female and male rats fed an obesogenic diet. ${ }^{77}$ Maternal iron deficiency has also been reported to lead to altered lipid metabolism and glucose tolerance in offspring although the effects on adiposity are less clear. ${ }^{58,79}$

\section{Maternal nutritional excess}

Epidemiological studies have demonstrated that fetal growth restriction correlates with adult disease, implying that fetal nutritional deprivation is a strong stimulus for developmental programming. ${ }^{80}$ Thus, experimental animal models were developed using controlled maternal caloric intake or protein or macronutrient deficiency. However, in many developed societies, maternal and postnatal caloric intake is either sufficient or excessive. Many studies have now modeled maternal nutritional excess using a number of different strategies, all resulting in an increase in the incidence of adult obesity, although the timing and the magnitude of the phenotype vary according to the nutritional insult. ${ }^{81-84}$ We have recently shown that a moderate maternal high-fat diet ( $45 \% \mathrm{kcal}$ from fat) results in significant obesity in male and female offspring, independent of postweaning diet (Figure 2B) ${ }^{84}$ During pregnancies which have been complicated by maternal diabetes, gestational diabetes, or impaired glucose tolerance, offspring have been shown to be at an enhanced risk of developing obesity. ${ }^{85}$ Thus, in keeping with the PAR theoretical framework, in response to a given in utero or early postnatal nutritional plane (either high or low), cellular processes are invoked to cope with the predicted environment. The PAR hypothesis suggests that disease manifests only when the actual nutritional environment diverges from that which was predicted. It is notable that there is evidence for the programming of obesity and several other features of the metabolic syndrome from both nutrient restriction (caloric, protein, and iron) and fat-feeding studies, possibly suggestive of a commonality of mechanism. ${ }^{80}$ Taken together, most experimental data derived from nutrition studies support the contention that the relationship among birth weight, metabolic compromise, and disease risk presents in a U-shaped curve with a higher prevalence of adult obesity occurring in individuals who were on either low or high planes of maternal nutrition. ${ }^{84,86-89}$

\section{Reversibility}

Until recently, developmental programming was seen to be an irreversible change in developmental trajectory, the consequences of which had to be managed, eg, obesity and type 2 diabetes. To date, few studies have addressed the possibility of reversibility or prevention of the postnatal programmed phenotype.

It has been proposed that deficiencies in the obesity hormone leptin during critical windows of development could lead to a hardwiring of obesity. ${ }^{90}$ In adult mammals, leptin acts on the brain to reduce food intake by regulating the 
activity of neurons in the arcuate nucleus of the hypothalamus (ARH). Bouret et $\mathrm{al}^{91,92}$ have shown that neural projection pathways from the ARH are permanently disrupted in leptindeficient $\left(\mathrm{Lep}^{\mathrm{ob}} / \mathrm{Lep}^{\mathrm{ob}}\right)$ mice. Treatment of Lep ${ }^{\mathrm{ob}} / \mathrm{Lep}^{\mathrm{ob}}$ neonates with exogenous leptin rescues the development of ARH projections, and leptin promotes neurite outgrowth from ARH neurons in vitro. In this regard, data exist demonstrating that cord blood leptin concentrations are significantly diminished in small for gestational age (SGA) babies, and as children, they are hypoleptinemic. These children go on to develop obesity and leptin resistance in adult life. ${ }^{93}$ Whether these children have disrupted ARH neural projections is unknown, but it may be that perturbations in perinatal nutrition that alter leptin levels may have enduring consequences for the formation and function of circuits that regulate food intake and body weight. $91,92,94,95$

An early-life modification in circulating leptin levels has been developed previously in our laboratory. ${ }^{46}$ Pups born to undernourished mothers are hypoleptinemic at birth and go on to develop obesity and metabolic compromise as adults. ${ }^{46}$ Daily leptin administration between 3-13 days of neonatal life in female rats born to undernourished mothers prevented the development of diet-induced obesity and associated metabolic sequelae in adult life (Figure 3$)^{96}$ and also normalized caloric intake, locomotor activity, body weight, fat mass,

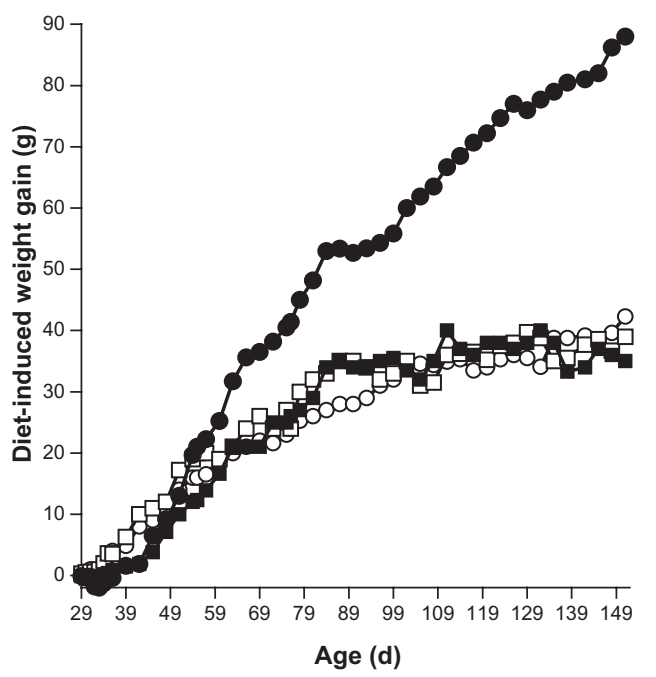

Figure 3 Diet-induced weight gain ( $\Delta$, high fat-chow fed) at postnatal day 170 in ad libitum fed (AD) and undernourished (UN) animals treated with either saline or leptin in the neonatal period. Neonatal leptin given to $\mathrm{UN}$ animals normalized dietinduced weight gain to match that of AD animals. Neonatal leptin had no effect on

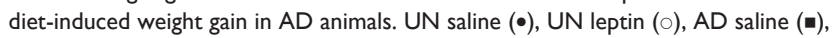
and $A D$ leptin ( $\square$ ). AD saline vs $A D$ leptin NS, UN leptin vs AD saline NS, UN leptin vs $A D$ leptin NS; UN saline $P<0.001$ vs all other groups.

Note: Copyright @ 2005. Modified with permission from The Endocrine Society. Vickers MH, Gluckman PD, Coveny AH, et al. Neonatal leptin treatment reverses developmental programming. Endocrinology. 2005; I46(I0):421।-4216.96

Abbreviation: NS, not significant. and fasting plasma glucose, insulin, C-peptide, and leptin concentrations suggestive of effects that were not restricted solely to a central mechanism. These improvements were specific to animals born to undernourished mothers; leptin had no effect in animals born to control mothers (Figure 3). The mechanisms underlying this reversibility are unclear, although the first 12 days of neonatal life in the rat are particularly plastic, and we speculate that the administration of leptin during this time reversed the cueing effects of prenatal undernutrition. ${ }^{97}$

The next piece to the puzzle is the question of the neonatal leptin surge. Although the surge is well characterized in rodents ${ }^{98}$ and may inform a window of intervention, the presence or absence of a leptin surge in human neonates is uncertain. It has recently been shown that neonatal leptin treatment to growth-retarded piglets can partially reverse the IUGR phenotype by correcting growth rate, body composition, and development of several organs involved in metabolic regulation. ${ }^{99}$ These data are consistent with those found in the rat, ${ }^{96}$ and the translation of findings across animal models itself bodes well for defining the role of leptin during this critical window of development.

Experiments in the rodent have also shown that administration of growth hormone $(\mathrm{GH})$ or insulin-like growth factor (IGF)-I can resolve several aspects of the metabolic phenotype in developmentally programmed offspring. GH treatment to hypertensive, obese, and hyperphagic adult rats born to calorie-restricted mothers ${ }^{46}$ normalized systolic blood pressure and reduced fat mass. ${ }^{100}$ However, this treatment was not without consequences, as the characteristic hyperinsulinemia found in these offspring was exacerbated with treatment due to the diabetogenic actions of GH. ${ }^{100}$ Comparably, clinical trials with GH in SGA children have shown a normalization in systolic blood pressure, which was maintained for the 6-year duration of treatment. ${ }^{101}$ IGF-I infusion in adult female offspring born to undernourished mothers led to a complete normalization of adiposity, appetite, fasting plasma insulin, and leptin concentrations. ${ }^{102}$ Together, these studies highlight the role of the somatotropic axis in programmed metabolic disturbances, although the longer-term efficacy of such treatment regimes is not known.

Other treatments have been shown to induce improvements in the "programmed" phenotype. Treatment of neonatal rats with the glucagon-like peptide (GLP)-1 analog exendin 4 (Ex-4) has been shown to reverse the adverse consequences of fetal growth restriction, and its administration prevented the development of diabetes in adulthood. ${ }^{103-105}$ Ex-4 prevented the progressive reduction in insulin-producing $\beta$-cell 
mass that is usually observed in growth-restricted rats, and the expression of pancreatic duodenal homeobox, a critical regulator of pancreatic development and islet differentiation, was restored to normal levels. Similarly, GLPs are known to modify food intake, increase satiety, delay gastric emptying, and suppress glucagon release, ${ }^{105,106}$ and further investigations into the long-term effects of Ex-4 on adiposity are now underway.

Rather than pharmacological therapies, nutritional interventions have also succeeded in rescuing offspring subjected to early-life compromise. Wyrwoll et al ${ }^{107}$ successfully rescued offspring of glucocorticoid-treated pregnant rats with a postnatal diet high in omega-3 fatty acids. Pregnant rats were treated with DEX from d13 to term, and offspring were crossfostered to mothers on either a standard diet or a diet high in omega-3 fatty acids and remained on these postweaning diets. Maternal DEX treatment reduced birth weight and resulted in hyperleptinemia and increased fat mass in offspring by 6 months of age. These effects were completely ameliorated, however, in offspring fed a high omega- 3 diet. These results demonstrated for the first time that direct manipulation of postnatal diet can limit adverse outcomes of developmental programming. With regard to maternal obesity, Giraudo et a ${ }^{83}$ have shown that even mild food restriction of obese mothers during pregnancy may have beneficial effects in reducing the risk or degree of obesity in offspring.

\section{Epigenetic mechanisms}

The concept of developmental plasticity in the generation of biological variation from one genotype has become of central interest in the field of developmental programming and has driven scientific interest in the clinical significance of epigenetic processes, particularly those influenced by the external environment. ${ }^{108}$

Experimental data in rodents and recent observations in humans suggest that epigenetic changes in regulatory and growth-related genes play a significant role in mediating the pathophysiological phenotypes derived from developmental programming. ${ }^{109,110}$ Epigenetic processes lead to heritable changes in gene function by altering DNA chemistry independent of sequence and may be responsible for tissue-specific gene expression during differentiation, and these mechanisms may underlie the processes of developmental plasticity. ${ }^{111}$ Examples of epigenetic regulation include coordinated changes in the methylation of cytosine in cytosine-guanine $(\mathrm{CpG})$ dinucleotides in the promoter regions of specific genes and changes in chromatin structure through histone modification (eg, acetylation, methylation) and posttranscriptional control by microRNA. ${ }^{111}$ Histone modifications in conjunction with DNA methylation regulate chromatin structure and gene expression. However, it is still debated where early-life and/or environmental factors can influence the "histone" code in a manner similar to their influence on DNA methylation. ${ }^{112}$

Adversity during pregnancy or early neonatal life in experimental programming models has been shown to result in changes in promoter methylation; thus, directly or indirectly affect gene expression in pathways associated with a range of physiologic processes. ${ }^{113}$ In the rat, altered promoter methylation and downstream changes in gene expression have been shown for the hepatic glucocorticoid receptor (GR) and the peroxisome proliferator-activated receptor $\alpha$ (PPAR$\alpha),{ }^{53,114}$ influencing carbohydrate and lipid metabolism. ${ }^{66,115}$ Similar epigenetic modifications have been observed in p53 in the kidney, ${ }^{116}$ in angiotensin II type $1 \mathrm{~b}$ receptor in the adrenal gland, ${ }^{117}$ and in central epigenetic regulation of hypothalamic GR, ${ }^{118,119}$ influencing renal apoptosis, pressor responses, and stress responses, respectively.

The phenotypic effects of epigenetic modifications during development may not manifest until later in life, especially if they affect genes modulating responses to later environmental challenges, such as dietary challenges with a high-fat diet. The timing of the developmental windows and the induction of epigenetic changes in key physiologic systems is not well characterized, but it appears to extend from the periconceptional period ${ }^{120}$ to postnatal life. ${ }^{118,119}$ Evidence exists from studies in twins for changes in the human epigenome related to age and the environment. ${ }^{121,122}$

Several studies have measured modifications in DNA methylation patterns to understand the impact of early-life nutrition on the epigenetic regulation of both imprinted and nonimprinted genes. ${ }^{109}$ Imprinted genes may show altered expression after perturbations during early development, such as if blastocyst culture in vitro is prolonged. ${ }^{123}$ Imprinted genes like $\operatorname{Igf2}$ and $H 19$ have been shown to be modified in offspring born to protein-restricted mothers, ${ }^{124}$ where hepatic $\operatorname{Ig} f 2$ messenger RNA (mRNA) levels were reduced in male fetuses but were unassociated with changes in DNA methylation. Intriguingly, the effects were restricted to those offspring born to mothers that were protein-restricted during the preimplantation period, but not throughout gestation, ${ }^{124}$ highlighting the need to consider critical developmental windows during development.

It is hypothesized that alterations in early-life nutrition can influence DNA methylation because one-carbon metabolism is dependent upon dietary methyl donors and cofactors, 
including folic acid, choline and vitamin B12. ${ }^{109,125}$ Maternal dietary manipulations such as low-protein exposure result in aberrant changes in DNA methylation in key genes that can be prevented by maternal dietary supplementation with cofactors. ${ }^{114}$ Protein restriction in pregnant rats has been shown to induce a significant loss of DNA methylation concomitant with increased expression of key hepatic genes, including the GR and PPAR- $\alpha .{ }^{114}$ These epigenetic changes, a result of altered DNA methyltransferase (DNMT)-1 mRNA levels, ${ }^{53}$ were prevented with maternal folate supplementation. ${ }^{114}$ Intriguingly, other models of early-life adversity, apart from nutrition, have also been shown to influence epigenetic regulation of gene expression. Meaney and colleagues have extensively investigated the role of maternal care during neonatal life on epigenetic regulation of gene expression patterns in the brains of offspring born to "low-caring" mothers. In their studies, they demonstrate that an increased level of maternal care in the first week of life alters DNA methylation at specific CpGs in the GR gene promoter in the hippocampus of the offspring and in turn leads to a phenotype similar to that of maternal undernutrition models. Reversal of the epigenetic change leads to reversal of the phenotypes. Furthermore, Meaney and colleagues showed that alterations in offspring behavior may be modified by postnatal environmental enrichment and that these phenotypes can be passed from one generation to the next. ${ }^{127-130}$ These results provide the evidence for the role of social conditions beyond the postnatal period in altering patterns of maternal care and thus offspring phenotype and illustrate the interaction between the effects of postnatal and postweaning environments. ${ }^{128,130}$

Waterland et al ${ }^{131,132}$ used mouse models to show that some alleles are particularly susceptible to maternal nutrition-induced changes in methylation. Supplementary nutrition can lead to increasing body weight across several generations of offspring and suggests that maternal nutrition before and during pregnancy may affect the establishment of CpG methylation and the life-long expression of metastable epialleles (epigenetically modified alleles) in humans. ${ }^{131}$ Prenatal undernutrition has also been shown to induce changes in histone $\mathrm{H} 3$ and $\mathrm{H} 4$ acetylation, consistent with facilitated transcription, in the GR gene in the liver. ${ }^{133}$ From a mechanistic standpoint, studies in humans linking epigenetic change to metabolic disease risk remain very limited although there is some evidence for the inheritance of tissue specific DNA methylation patterns. ${ }^{134}$ Differences in environmental exposure lead to different patterns of epigenetic marking in the somatic tissues of individuals, as evidenced by studies in twins in which DNA methylation and histone acetylation patterns diverged more strongly in older twin pairs with more marked life history differences. ${ }^{122}$

It has been shown that the promoter in the leptin gene is subject to epigenetic programming, and leptin gene expression can be modulated by DNA methylation. ${ }^{135-137}$ Yokomori et al showed that methylation of 7 of the $\mathrm{CpG}$ sites in the leptin gene promoter was associated with adipocyte differentiation in 3T3-L1 cells. Here, a methylation-sensitive $52 \mathrm{kMr}$ nuclear protein was associated with the methylated leptin promoter and facilitated the repression of transcription in a fashion that is similar to methyl $\mathrm{CpG}$-binding protein $2 .{ }^{138}$ The same laboratory group has also shown that both methylation of specific $\mathrm{CpG}$ sites and a methylationsensitive transcription factor contribute to GLUT4 gene regulation during preadipocyte to adipocyte differentiation. ${ }^{139}$ In addition, differential DNA methylation was observed in promoters of genes involved in glucose metabolism, including GLUT4 ${ }^{139}$ and uncoupling protein $2,{ }^{140}$ both major targets involved in the development of type 2 diabetes.

Recent reports have begun to highlight the importance of other regulatory factors, including SIRT1. ${ }^{141,142}$ The sirtuin family of nicotinamide adenine dinucleotide $\left(\mathrm{NAD}^{+}\right)_{-}^{-}$ dependent protein deacetylases regulates adipogenesis, lipolysis, and hepatic gluconeogenesis among a number of other metabolic and regulatory pathways (Holness et $\mathrm{al}^{141}$ ). Maternal nutrition in the rat has been shown to affect the expression of SIRT1 in offspring at weaning and has been attributed to a prolonged life span, ${ }^{143}$ possibly through its actions on PPAR- $\alpha$ and GR signaling. ${ }^{141}$ Importantly, SIRT1 facilitates histone deacetylation and deacetylation of a number of nonhistone targets, including PPAR- $\gamma$ coactivator-1 (PGC-1). PGC-1 plays a critical role in fuel homeostasis, promoting hepatic gluconeogenesis and lipogenesis and functionally interacts with PPAR- $\alpha$ and PPAR- $\gamma .{ }^{141}$ Clearly, SIRT1 and other members of the sirtuin family will become the focus of intensive investigation in the field of early-life nutritional adversity, risk of obesity, and metabolic compromise.

Epigenetic regulators work on the basis that exposure to environmental factors during critical periods of development permanently alter the structure or function of specific metabolic systems. Therefore, developmental epigenetics is believed to establish "adaptive phenotypes" to meet the demands of the later-life environment. ${ }^{12,144}$ Implicit in this concept is an important process of causality on the cellular level, regulating growth and tissue differentiation and involving chemical changes to the DNA or of associated proteins. As the epigenetic processes are potentially reversible, once the mechanistic basis of the disease is understood, 
intervention and strategies aimed at reversal could be devised and implemented. However, there are still many key questions to be answered: ${ }^{112}$ How plastic is the system for intervention and reversal? What are the critical windows of development at which strategies should be targeted? How many generations does it take to reverse an epigenetic imprint? Can surrogate markers be used for disease prediction?

\section{Conclusion}

Epidemiological studies have described a relationship between adverse perinatal factors and the development of metabolic disease and obesity in later life (Figure 4). Both prospective and retrospective clinical studies and experimental research have clearly shown that the propensity to develop obesity in later life is increased when early-life development has been adversely affected. The pathogenesis is not based on genetic defects but on altered gene expression as a consequence of an adaptation to environmental changes during early-life development. It is clear that lifestyle factors play a major role in the development of obesity and metabolic compromise; however, little is known about the interaction between the prenatal and postnatal nutritional environments on either amplification or resolution of the programming phenotype depending on the degree of nutritional match or mismatch. Thus, experiments aimed at examining the PAR hypothesis are required in conjunction with transgenerational work to further the developmental programming field.

An understanding of the molecular mechanisms underlying developmental programming is only recently beginning to come into light. Investigation of the role of epigenetics in modulating postnatal phenotype holds great promise in understanding the mechanisms underlying the link between earlylife adversity and postnatal risk of disease and in advancing their diagnosis, prevention, and treatment. A collection of drugs targeting epigenetic regulation (DNMT inhibitors and histone deacetylase inhibitors) already exists at various stages of development, and although their effectiveness has yet to be maximized, they may show great promise in the treatment of complex disease such as the metabolic syndrome. ${ }^{145}$

The incidence of obesity and metabolic disorders is increasing worldwide and likely will contribute to major economic, psychological, and social burden. Currently, the

(undernutrition, maternal obesity, gestational diabetes)

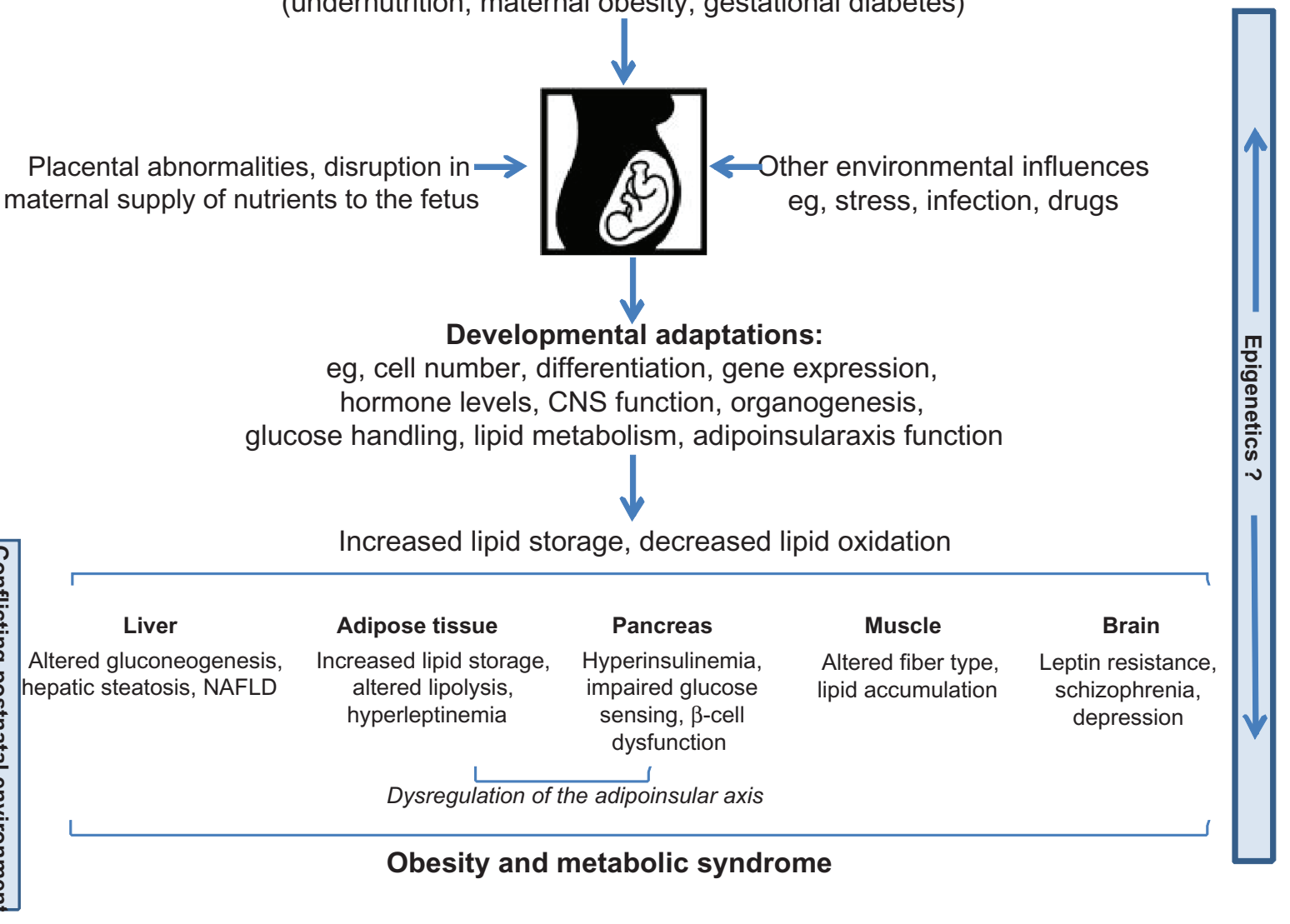

Figure 4 Schematic illustration showing the developmental pathways to obesity and metabolic syndrome following adverse early-life events. Abbreviations: CNS, central nervous system; NAFLD, non-alcoholic fatty liver disease. 
impact of global nutritional environments on health and disease risk is poorly understood, but improved insight into underlying mechanisms is likely to have a significant impact on not only our current understanding of disease risk but also our understanding of disease risk in future generations. Understanding the impact of early-life events on health offers a novel approach to investigate the mechanistic basis of obesity and related metabolic disorders, which in human populations was believed to predominantly arise from lifestyle choices. A recent emerging focus has been on studies aimed at reversing the programmed phenotype; such studies offer an exciting potential for new advances in our understanding of critical determinants and mechanisms for human obesity and metabolic disorders.

\section{Acknowledgments}

The authors would like to acknowledge funding support from the Health Research Council of New Zealand, the Foundation for Research, Science and Technology, the Marsden Fund of the Royal Society of New Zealand, and the National Research Centre for Growth and Development.

\section{Disclosure}

The authors report no conflicts of interest in this work.

\section{References}

1. Seidell JC. Prevention of obesity: the role of the food industry. Nutr Metab Cardiovasc Dis. 1999;9(1):45-50.

2. Seidell JC. Obesity, insulin resistance and diabetes - a worldwide epidemic. Br J Nutr. 2000;83 Suppl 1:S5-S8.

3. Bell CG, Walley AJ, Froguel P. The genetics of human obesity. Nat Rev Genet. 2005;6(3):221-234.

4. Ravelli AC, van Der Meulen JH, Osmond C, Barker DJ, Bleker OP. Obesity at the age of $50 \mathrm{y}$ in men and women exposed to famine prenatally. Am J Clin Nutr. 1999;70(5):811-816.

5. Godfrey KM, Barker DJ. Fetal nutrition and adult disease. Am J Clin Nutr. 2000;71 Suppl 5:1344S-1352S.

6. Breier BH, Vickers MH, Ikenasio BA, Chan KY, Wong WP. Fetal programming of appetite and obesity. Mol Cell Endocrinol. 2001; 185(1-2):73-79.

7. Hanson MA, Gluckman PD. Developmental origins of health and disease: new insights. Basic Clin Pharmacol Toxicol. 2008;102(2):90-93.

8. Gluckman PD, Hanson MA, Spencer HG. Predictive adaptive responses and human evolution. Trends Ecol Evol. 2005;20(10):527-533.

9. Godfrey KM, Gluckman PD, Hanson MA. Developmental origins of metabolic disease: life course and intergenerational perspectives. Trends Endocrinol Metab. 2010;21(4):199-205.

10. Gluckman PD, Hanson MA, Beedle AS. Early life events and their consequences for later disease: a life history and evolutionary perspective. Am J Hum Biol. 2007;19(1):1-19.

11. Gluckman PD, Hanson MA, Beedle AS. Non-genomic transgenerational inheritance of disease risk. Bioessays. 2007;29(2):145-154.

12. Stettler N, Iotova V. Early growth patterns and long-term obesity risk. Curr Opin Clin Nutr Metab Care. 2010;13(3):294-299.

13. Barker DJP, Osmond C. Infant mortality, childhood nutrition, and ischaemic heart disease in England and Wales. Lancet. 1986;1(8489): 1077-1081.
14. Barker DJP, Winter PD, Osmond C, Margetts B, Simmonds SJ. Weight in infancy and death from ischaemic heart disease. Lancet. 1989;8663:577-580.

15. Barker DJP, Bull AR, Osmond C, Simmonds SJ. Fetal and placental size and risk of hypertension in adult life. Br Med J. 1990;301(6746): 259-262.

16. Osmond C, Barker DJ, Slattery JM. Risk of death from cardiovascular disease and chronic bronchitis determined by place of birth in England and Wales. J Epidemiol Community Health. 1990;44(2):139-141.

17. Ravelli GP, Stein ZA, Susser MW. Obesity in young men after famine exposure in utero and early infancy. $N$ Engl J Med. 1976;295(7): 349-353.

18. Roseboom TJ, van der Meulen JH, Ravelli AC, et al. Blood pressure in adults after prenatal exposure to famine. J Hypertens. 1999;17(3): 325-330.

19. Roseboom TJ, van der Meulen JH, Ravelli AC, Osmond C, Barker DJ, Bleker OP. Effects of prenatal exposure to the Dutch famine on adult disease in later life: an overview. Mol Cell Endocrinol. 2001;185(1-2): 93-98.

20. Stanner SA, Yudkin JS. Fetal programming and the Leningrad Siege study. Twin res. 2001;4(5):287-292.

21. Barker DJ. Low intelligence. Its relation to length of gestation and rate of foetal growth. Br J Prev Soc Med. 1966;20(2):58-66.

22. Hales CN, Ozanne SE. For debate: fetal and early postnatal growth restriction lead to diabetes, the metabolic syndrome and renal failure. Diabetologia. 2003;46(7):1013-1019.

23. Ong KK, Ahmed ML, Emmett PM, Preece MA, Dunger DB. Association between postnatal catch-up growth and obesity in childhood: prospective cohort study. BMJ. 2000;320(7240):967-971.

24. Ibanez L, Ong K, Dunger DB, de Zegher F. Early development of adiposity and insulin resistance after catch-up weight gain in smallfor-gestational-age children. J Clin Endocrinol Metab. 2006;91(6): 2153-2158.

25. Ibanez L, Suarez L, Lopez-Bermejo A, Diaz M, Valls C, de Zegher F. Early development of visceral fat excess after spontaneous catch-up growth in children with low birth weight. J Clin Endocrinol Metab. 2008;93(3):925-928.

26. Eriksson JG. Early growth, and coronary heart disease and type 2 diabetes: experiences from the Helsinki Birth Cohort Studies. Int J Obes (Lond). 2006;30 Supp1 4:S18-S22.

27. Yajnik C. Interactions of perturbations in intrauterine growth and growth during childhood on the risk of adult-onset disease. Proc Nutr Soc. 2000;59(2):257-265.

28. Eriksson JG, Forsen T, Tuomilehto J, Winter PD, Osmond C, Barker DJ. Catch-up growth in childhood and death from coronary heart disease: longitudinal study. BMJ. 1999;318(7181):427-431.

29. Parsons TJ, Power C, Manor O. Fetal and early life growth and body mass index from birth to early adulthood in 1958 British cohort: longitudinal study. BMJ. 2001;323(7325):1331-1335.

30. Eriksson J, Forsen T, Osmond C, Barker D. Obesity from cradle to grave. Int j obes relat metab disord. 2003;27(6):722-727.

31. Fetita LS, Sobngwi E, Serradas P, Calvo F, Gautier JF. Consequences of fetal exposure to maternal diabetes in offspring. J Clin Endocrinol Metab. 2006;91(10):3718-3724.

32. Gillman MW, Rifas-Shiman S, Berkey CS, Field AE, Colditz GA. Maternal gestational diabetes, birth weight, and adolescent obesity. Pediatrics. 2003;111(3):e221-e226.

33. Lampl M, Jeanty P. Exposure to maternal diabetes is associated with altered fetal growth patterns: a hypothesis regarding metabolic allocation to growth under hyperglycemic-hypoxemic conditions. Am J Hum Biol. 2004;16(3):237-263.

34. Silverman BL, Metzger BE, Cho NH, Loeb CA. Impaired glucose tolerance in adolescent offspring of diabetic mothers. Relationship to fetal hyperinsulinism. Diabetes Care. 1995;18(5):611-617.

35. Catalano PM. Increasing maternal obesity and weight gain during pregnancy: the obstetric problems of plentitude. Obstet Gynecol. 2007; 110(4):743-744. 
36. Jonathan R, Jennifer B, Mark M. Maternal obesity and pregnancy complications: a review. Aust N Z J Obstet Gynaecol. 2008;48(3): 228-235.

37. Catalano PM, Farrell K, Thomas A, et al. Perinatal risk factors for childhood obesity and metabolic dysregulation. Am J Clin Nutr. 2009; 90(5):1303-1313.

38. Boney CM, Verma A, Tucker R, Vohr BR. Metabolic syndrome in childhood: association with birth weight, maternal obesity, and gestational diabetes mellitus. Pediatrics. 2005;115(3):e290-e296.

39. Kristensen J, Vestergaard H, Wisborg K, Kesmodel U, Secher U. Pre-pregnancy weight and the risk of stillbirth and neonatal death. BJOG. 2005;112(4):403-408.

40. Shankar K, Harrell A, Liu X, Gilchrist JM, Ronis MJ, Badger TM. Maternal obesity at conception programs obesity in the offspring. Am J Physiol Regul Integr Comp Physiol. 2008;294(2):R528-R538.

41. Armitage JA, Poston L, Taylor PD. Developmental origins of obesity and the metabolic syndrome: the role of maternal obesity. Front Horm Res. 2008;36:73-84

42. Crozier SR, Inskip HM, Godfrey KM, et al. Weight gain in pregnancy and childhood body composition: findings from the Southampton Women's Survey. Am J Clin Nutr. 2010;91(6):1745-1751.

43. Barker DJ. Obesity and early life. Obes Rev. 2007;8 Suppl 1:45-49.

44. Barker DJ. The origins of the developmental origins theory. J Intern Med. 2007;261(5):412-417.

45. McArdle HJ, Andersen HS, Jones H, Gambling L. Fetal programming: causes and consequences as revealed by studies of dietary manipulation in rats - a review. Placenta. 2006;27 Suppl A:S56-S60.

46. Vickers MH, Breier BH, Cutfield WS, Hofman PL, Gluckman PD. Fetal origins of hyperphagia, obesity, and hypertension and postnatal amplification by hypercaloric nutrition. Am J Physiol Endocrinol Metab. 2000;279(1):E83-E87.

47. Vickers MH, Breier BH, McCarthy D, Gluckman PD. Sedentary behavior during postnatal life is determined by the prenatal environment and exacerbated by postnatal hypercaloric nutrition. Am J Physiol Regul Integr Comp Physiol. 2003;285(1):R271-R273.

48. Vickers MH, Reddy S, Ikenasio BA, Breier BH. Dysregulation of the adipoinsular axis - a mechanism for the pathogenesis of hyperleptinemia and adipogenic diabetes induced by fetal programming. J Endocrinol. 2001;170(2):323-332.

49. Woodall SM, Johnston BM, Breier BH, Gluckman PD. Chronic maternal undernutrition in the rat leads to delayed postnatal growth and elevated blood pressure of offspring. Pediatr Res. 1996;40(3):438-443.

50. Woodall SM, Breier BH, Johnston BM, Gluckman PD. A model of intrauterine growth retardation caused by chronic maternal undernutrition in the rat: effects on the somatotrophic axis and postnatal growth. J Endocrinol. 1996;150(2):231-242.

51. Langley-Evans SC, Welham SJ, Jackson AA. Fetal exposure to a maternal low protein diet impairs nephrogenesis and promotes hypertension in the rat. Life Sci. 1999;64(11):965-974.

52. Langley-Evans SC. Metabolic programming in pregnancy: studies in animal models. Genes Nutr. 2007;2(1):33-38.

53. Lillycrop KA, Slater-Jefferies JL, Hanson MA, Godfrey KM, Jackson AA, Burdge GC. Induction of altered epigenetic regulation of the hepatic glucocorticoid receptor in the offspring of rats fed a proteinrestricted diet during pregnancy suggests that reduced DNA methyltransferase-1 expression is involved in impaired DNA methylation and changes in histone modifications. Br J Nutr. 2007;97(6):1064-1073.

54. Rajakumar PA, He J, Simmons RA, Devaskar SU. Effect of uteroplacental insufficiency upon brain neuropeptide $\mathrm{Y}$ and corticotropinreleasing factor gene expression and concentrations. Pediatr Res. 1998;44(2):168-174.

55. Simmons RA, Templeton LJ, Gertz SJ. Intrauterine growth retardation leads to the development of type 2 diabetes in the rat. Diabetes. 2001; 50(10):2279-2286.

56. Simmons RA. Role of metabolic programming in the pathogenesis of beta-cell failure in postnatal life. Rev Endocr Metab Disord. 2007; $8(2): 95-104$.
57. Nyirenda MJ, Lindsay RS, Kenyon CJ, Burchell A, Seckl JR Glucocorticoid exposure in late gestation permanently programs rat hepatic phosphoenolpyruvate carboxykinase and glucocorticoid receptor expression and causes glucose intolerance in adult offspring. J Clin Invest. 1998;101(10):2174-2181.

58. Lewis RM, Forhead AJ, Petry CJ, Ozanne SE, Hales CN. Long-term programming of blood pressure by maternal dietary iron restriction in the rat. Br J Nutr. 2002;88(3):283-290.

59. Dahlgren J, Nilsson C, Jennische E, et al. Prenatal cytokine exposure results in obesity and gender-specific programming. Am J Physiol Endocrinol Metab. 2001;281(2):E326-E334.

60. Barker DJ, Osmond C, Golding J, Kuh D, Wadsworth ME. Growth in utero, blood pressure in childhood and adult life, and mortality from cardiovascular disease. BMJ. 1989;298(6673):564-567.

61. Snoeck A, Remacle C, Reusens B, Hoet JJ. Effect of a low protein diet during pregnancy on the fetal rat endocrine pancreas. Biol Neonate. 1990;57(2):107-118.

62. Langley SC, Jackson AA. Increased systolic blood pressure in adult rats induced by fetal exposure to maternal low protein diets. Clin Sci (Lond). 1994;86(2):217-222; discussion 121.

63. Desai M, Crowther NJ, Lucas A, Hales CN. Organ-selective growth in the offspring of protein-restricted mothers. Br J Nutr. 1996;76(4):591-603.

64. Ozanne SE, Constancia M. Mechanisms of disease: the developmental origins of disease and the role of the epigenotype. Nat Clin Pract Endocrinol Metab. 2007;3(7):539-546.

65. Petry CJ, Ozanne SE, Hales CN. Programming of intermediary metabolism. Mol Cell Endocrinol. 2001;185(1-2):81-91.

66. Burdge GC, Slater-Jefferies J, Torrens C, Phillips ES, Hanson MA Lillycrop KA. Dietary protein restriction of pregnant rats in the F0 generation induces altered methylation of hepatic gene promoters in the adult male offspring in the F1 and F2 generations. Br J Nutr. 2007;97(3):435-439.

67. Langley-Evans SC. Critical differences between two low protein diet protocols in the programming of hypertension in the rat. Int J Food Sci Nutr. 2000;51(1):11-17.

68. Jennings BJ, Ozanne SE, Dorling MW, Hales CN. Early growth determines longevity in male rats and may be related to telomere shortening in the kidney. FEBS Lett. 1999;448(1):4-8.

69. Cottrell EC, Ozanne SE. Developmental programming of energy balance and the metabolic syndrome. Proc Nutr Soc. 2007;66(2):198-206.

70. Ozanne SE, Dorling MW, Wang CL, Nave BT. Impaired PI 3-kinase activation in adipocytes from early growth-restricted male rats. $\mathrm{Am} \mathrm{J}$ Physiol Endocrinol Metab. 2001;280(3):E534-E539.

71. Ozaki T, Nishina H, Hanson MA, Poston L. Dietary restriction in pregnant rats causes gender-related hypertension and vascular dysfunction in offspring. J Physiol. 2001;530(Pt 1):141-152.

72. Krechowec SO, Vickers M, Gertler A, Breier BH. Prenatal influences on leptin sensitivity and susceptibility to diet-induced obesity. J Endocrinol. 2006;189(2):355-363.

73. Desai M, Gayle D, Babu J, Ross MG. Programmed obesity in intrauterine growth-restricted newborns: modulation by newborn nutrition. Am J Physiol Regul Integr Comp Physiol. 2005;288(1):R91-R96.

74. Padmavathi IJ, Kishore YD, Venu L, et al. Prenatal and perinatal zinc restriction: effects on body composition, glucose tolerance and insulin response in rat offspring. Exp Physiol. 2009;94(6):761-769.

75. Venu L, Padmavathi IJ, Kishore YD, et al. Long-term effects of maternal magnesium restriction on adiposity and insulin resistance in rat pups. Obesity (Silver Spring). 2008;16(6):1270-1276.

76. Venu L, Kishore YD, Raghunath M. Maternal and perinatal magnesium restriction predisposes rat pups to insulin resistance and glucose intolerance. J Nutr. 2005;135(6):1353-1358

77. Venu L, Harishankar N, Prasanna Krishna T, Raghunath M. Maternal dietary vitamin restriction increases body fat content but not insulin resistance in WNIN rat offspring up to 6 months of age. Diabetologia. 2004;47(9):1493-1501.

78. Padmavathi IJN, Rao KR, Venu L, et al. Chronic maternal dietary chromium restriction modulates visceral adiposity. Diabetes. 2010;59(1): 98-104. 
79. Lewis RM, Petry CJ, Ozanne SE, Hales CN. Effects of maternal iron restriction in the rat on blood pressure, glucose tolerance, and serum lipids in the 3-month-old offspring. Metabolism. 2001;50(5): $562-567$.

80. Armitage JA, Khan IY, Taylor PD, Nathanielsz PW, Poston L. Developmental programming of the metabolic syndrome by maternal nutritional imbalance: how strong is the evidence from experimental models in mammals?. J Physiol. 2004;561(Pt 2):355-377.

81. Bayol SA, Simbi BH, Fowkes RC, Stickland NC. A maternal “junk food" diet in pregnancy and lactation promotes nonalcoholic fatty liver disease in rat offspring. Endocrinology. 2010;151(4):1451-1461.

82. Szeto IMY, Das PJ, Aziz A, Anderson GH. Multivitamin supplementation of Wistar rats during pregnancy accelerates the development of obesity in offspring fed an obesogenic diet. Int J Obes (Lond). 2009; 33(3):364-372.

83. Giraudo SQ, Della-Fera MA, Proctor L, Wickwire K, Ambati S, Baile CA. Maternal high fat feeding and gestational dietary restriction: effects on offspring body weight, food intake and hypothalamic gene expression over three generations in mice. Pharmacol Biochem Behav. In press 2010.

84. Howie GJ, Sloboda DM, Kamal T, Vickers MH. Maternal nutritional history predicts obesity in adult offspring independent of postnatal diet. J Physiol. 2009;587(Pt 4):905-915.

85. Holemans K, Caluwaerts S, Poston L, van Assche FA. Diet-induced obesity in the rat: a model for gestational diabetes mellitus. Am JObstet Gynecol. 2004;190(3):858-865.

86. Armitage JA, Taylor PD, Poston L. Experimental models of developmental programming: consequences of exposure to an energy rich diet during development. $J$ Physiol. 2005;565(Pt 1):3-8.

87. McMillen IC, Robinson JS. Developmental origins of the metabolic syndrome: prediction, plasticity, and programming. Physiol Rev. 2005; 85(2):571-633.

88. Samuelsson AM, Matthews PA, Argenton M, et al. Diet-induced obesity in female mice leads to offspring hyperphagia, adiposity, hypertension, and insulin resistance: a novel murine model of developmental programming. Hypertension. 2008;51(2):383-392.

89. Morris MJ, Chen H. Established maternal obesity in the rat reprograms hypothalamic appetite regulators and leptin signaling at birth. Int J Obes (Lond). 2009;33(1):115-122.

90. Horvath TL, Bruning JC. Developmental programming of the hypothalamus: a matter of fat. Nat Med. 2006;12(1):52-53; discussion 53.

91. Bouret SG, Draper SJ, Simerly RB. Trophic action of leptin on hypothalamic neurons that regulate feeding. Science. 2004;304(5667): 108-110.

92. Bouret SG, Draper SJ, Simerly RB. Formation of projection pathways from the arcuate nucleus of the hypothalamus to hypothalamic regions implicated in the neural control of feeding behavior in mice. J Neurosci. 2004;24(11):2797-2805.

93. Iniguez G, Soto N, Avila A, et al. Adiponectin levels in the first two years of life in a prospective cohort: relations with weight gain, leptin levels and insulin sensitivity. J Clin Endocrinol Metab. 2004; 89(11):5500-5503.

94. Elmquist JK, Ahima RS, Elias CF, Flier JS, Saper CB. Leptin activates distinct projections from the dorsomedial and ventromedial hypothalamic nuclei. Proc Natl Acad Sci U S A. 1998;95(2):741-746.

95. Bouret SG, Simerly RB. Development of leptin-sensitive circuits. J Neuroendocrinol. 2007;19(8):575-582.

96. Vickers MH, Gluckman PD, Coveny AH, et al. Neonatal leptin treatment reverses developmental programming. Endocrinology. 2005; 146(10):4211-4216.

97. Gluckman PD, Lillycrop KA, Vickers MH, et al. Metabolic plasticity during mammalian development is directionally dependent on early nutritional status. Proc Natl Acad Sci U S A. 2007;104(31):12796-12800.

98. Ahima RS, Prabakaran D, Flier JS. Postnatal leptin surge and regulation of circadian rhythm of leptin by feeding. Implications for energy homeostasis and neuroendocrine function. J Clin Invest. 1998;101(5): $1020-1027$.
99. Attig L, Djiane J, Gertler A, et al. Study of hypothalamic leptin receptor expression in low-birth-weight piglets and effects of leptin supplementation on neonatal growth and development. Am J Physiol Endocrinol Metab. 2008;295(5):E1117-E1125.

100. Vickers MH, Ikenasio BA, Breier BH. Adult growth hormone treatment reduces hypertension and obesity induced by an adverse prenatal environment. $J$ Endocrinol. 2002;175(3):615-623.

101. Sas T, Mulder P, Hokken-Koelega A. Body composition, blood pressure, and lipid metabolism before and during long-term growth hormone $(\mathrm{GH})$ treatment in children with short stature born small for gestational age either with or without GH deficiency. J Clin Endocrinol Metab. 2000;85(10):3786-3792.

102. Vickers MH, Ikenasio BA, Breier BH. IGF-I treatment reduces hyperphagia, obesity, and hypertension in metabolic disorders induced by fetal programming. Endocrinology. 2001;142(9):3964-3973.

103. Stoffers DA, Desai BM, DeLeon DD, Simmons RA. Neonatal exendin-4 prevents the development of diabetes in the intrauterine growth retarded rat. Diabetes. 2003;52(3):734-740.

104. Park JH, Stoffers DA, Nicholls RD, Simmons RA. Development of type 2 diabetes following intrauterine growth retardation in rats is associated with progressive epigenetic silencing of Pdx 1 . JClin Invest. 2008;118(6):2316-2324.

105. Raab EL, Vuguin PM, Stoffers DA, Simmons RA. Neonatal exendin-4 treatment reduces oxidative stress and prevents hepatic insulin resistance in intrauterine growth retarded rats. Am J Physiol Regul Integr Comp Physiol. 2009;297(6):R1785-R1794.

106. Freeman JS. Role of the incretin pathway in the pathogenesis of type 2 diabetes mellitus. Cleve Clin J Med. 2009;76 Suppl 5:S12-S19.

107. Wyrwoll CS, Mark PJ, Mori TA, Puddey IB, Waddell BJ. Prevention of programmed hyperleptinemia and hypertension by postnatal dietary omega-3 fatty acids. Endocrinology. 2006;147(1):599-606.

108. Gluckman PD, Beedle AS, Hanson MA, Yap EP. Developmental perspectives on individual variation: implications for understanding nutritional needs. Nestle Nutr Workshop Ser Pediatr Program. 2008; 62:1-9; disucssion 9-12.

109. Gicquel C, El-Osta A, Le Bouc Y. Epigenetic regulation and fetal programming. Best Pract Res Clin Endocrinol Metab. 2008;22(1):1-16.

110. Szyf M. Epigenetics, DNA methylation, and chromatin modifying drugs. Аnпu Rev Pharmacol Toxicol. 2009;49:243-263.

111. Gluckman PD, Hanson MA, Cooper C, Thornburg KL. Effect of in utero and early-life conditions on adult health and disease. $N$ Engl $J$ Med. 2008;359(1):61-73.

112. Tang WY, Ho SM. Epigenetic reprogramming and imprinting in origins of disease. Rev Endocr Metab Disord. 2007;8(2):173-182.

113. Jirtle RL, Skinner MK. Environmental epigenomics and disease susceptibility. Nat Rev Genet. 2007;8(4):253-262.

114. Lillycrop KA, Phillips ES, Jackson AA, Hanson MA, Burdge GC. Dietary protein restriction of pregnant rats induces and folic acid supplementation prevents epigenetic modification of hepatic gene expression in the offspring. $J$ Nutr. 2005;135(6):1382-1386.

115. Burdge GC, Lillycrop KA, Jackson AA, Gluckman PD, Hanson MA. The nature of the growth pattern and of the metabolic response to fasting in the rat are dependent upon the dietary protein and folic acid intakes of their pregnant dams and post-weaning fat consumption. Br J Nutr. 2008;99(3):540-549.

116. Pham TD, MacLennan NK, Chiu CT, Laksana GS, Hsu JL, Lane RH. Uteroplacental insufficiency increases apoptosis and alters p53 gene methylation in the full-term IUGR rat kidney. Am J Physiol Regul Integr Comp Physiol. 2003;285(5):R962-R970.

117. Bogdarina I, Welham S, King PJ, Burns SP, Clark AJ. Epigenetic modification of the renin-angiotensin system in the fetal programming of hypertension. Circ Res. 2007;100(4):520-526.

118. Weaver IC, Diorio J, Seckl JR, Szyf M, Meaney MJ. Early environmental regulation of hippocampal glucocorticoid receptor gene expression: characterization of intracellular mediators and potential genomic target sites. Ann NY Acad Sci. 2004;1024:182-212. 
119. Weaver IC, Cervoni N, Champagne FA, et al. Epigenetic programming by maternal behavior. Nat Neurosci. 2004;7(8):847-854.

120. Sinclair KD, Allegrucci C, Singh R, et al. DNA methylation, insulin resistance, and blood pressure in offspring determined by maternal periconceptional B vitamin and methionine status. Proc Natl Acad Sci USA. 2007;104(49):19351-19356.

121. Poulsen P, Esteller M, Vaag A, Fraga MF. The epigenetic basis of twin discordance in age-related diseases. Pediatr Res. 2007;61(5 Pt 2): $38 \mathrm{R}-42 \mathrm{R}$

122. Fraga MF, Ballestar E, Paz MF, et al. Epigenetic differences arise during the lifetime of monozygotic twins. Proc Natl Acad Sci U SA. 2005;102(30):10604-10609.

123. Doherty AS, Mann MR, Tremblay KD, Bartolomei MS, Schultz RM. Differential effects of culture on imprinted H19 expression in the preimplantation mouse embryo. Biol Reprod. 2000;62(6):1526-1535.

124. Kwong WY, Miller DJ, Ursell E, et al. Imprinted gene expression in the rat embryo-fetal axis is altered in response to periconceptional maternal low protein diet. Reproduction. 2006;132(2):265-277.

125. MacLennan NK, James SJ, Melnyk S, et al. Uteroplacental insufficiency alters DNA methylation, one-carbon metabolism, and histone acetylation in IUGR rats. Physiol Genomics. 2004;18(1):43-50.

126. Meaney MJ, Brake W, Gratton A. Environmental regulation of the development of mesolimbic dopamine systems: a neurobiological mechanism for vulnerability to drug abuse? sychoneuroendocrinology. 2002;27(1-2):127-138.

127. Meaney MJ, Szyf M. Environmental programming of stress responses through DNA methylation: life at the interface between a dynamic environment and a fixed genome. Dialogues Clin Neurosci. 2005;7(2):103-123.

128. Champagne DL, Bagot RC, van Hasselt F, et al. Maternal care and hippocampal plasticity: evidence for experience-dependent structural plasticity, altered synaptic functioning, and differential responsiveness to glucocorticoids and stress. J Neurosci. 2008;28(23):6037-6045.

129. Cameron NM, Shahrokh D, Del Corpo A, et al. Epigenetic programming of phenotypic variations in reproductive strategies in the rat through maternal care. J Neuroendocrinology. 2008;20(6):795-801.

130. Champagne FA, Francis DD, Mar A, Meaney MJ. Variations in maternal care in the rat as a mediating influence for the effects of environment on development. Physiol Behav. 2003;79(3):359-371.

131. Waterland RA, Michels KB. Epigenetic epidemiology of the developmental origins hypothesis. Annu Rev Nutr. 2007;27:363-388.

132. Waterland RA, Dolinoy DC, Lin JR, Smith CA, Shi X, Tahiliani KG. Maternal methyl supplements increase offspring DNA methylation at Axin Fused. Genesis. 2006;44(9):401-406.
133. Lillycrop KA, Jackson AA, Hanson MA, Burdge GC. Dietary protein restriction in the pregnant rat induces altered covalent modifications to histones at the glucocorticoid receptor promoter in the liver of the offspring after weaning. Proc Nutr Soc. 2006;65:108A.

134. Silva AJ, White R. Inheritance of allelic blueprints for methylation patterns. Cell. 1988;54(2):145-152.

135. Iliopoulos D, Malizos KN, Tsezou A. Epigenetic regulation of leptin affects MMP-13 expression in osteoarthritic chondrocytes: possible molecular target for osteoarthritis therapeutic intervention. Ann Rheum Dis. 2007;66(12):1616-1621.

136. Melzner I, Scott V, Dorsch K, et al. Leptin gene expression in human preadipocytes is switched on by maturation-induced demethylation of distinct CpGs in its proximal promoter. J Biol Chem. 2002; 277(47):45420-45427.

137. Stoger R. In vivo methylation patterns of the leptin promoter in human and mouse. Epigenetics. 2006;1(4):155-162.

138. Yokomori N, Tawata M, Onaya T. DNA demethylation modulates mouse leptin promoter activity during the differentiation of 3T3-L1 cells. Diabetologia. 2002;45(1):140-148.

139. Yokomori N, Tawata M, Onaya T. DNA demethylation during the differentiation of 3T3-L1 cells affects the expression of the mouse GLUT4 gene. Diabetes. 1999;48(4):685-690.

140. Carretero MV, Torres L, Latasa U, et al. Transformed but not normal hepatocytes express UCP2. FEBS Lett. 1998;439(1-2):55-58.

141. Holness MJ, Caton PW, Sugden MC. Acute and long-term nutrient-led modifications of gene expression: potential role of SIRT1 as a central co-ordinator of short and longer-term programming of tissue function. Nutrition. 2010;26(5):491-501.

142. Chen JH, Martin-Gronert MS, Tarry-Adkins J, Ozanne SE. Maternal protein restriction affects postnatal growth and the expression of key proteins involved in lifespan regulation in mice. PLOS ONE. 2009; 4(3): 4950

143. Martin-Gronert MS, Tarry-Adkins JL, Cripps RL, Chen JH, Ozanne SE. Maternal protein restriction leads to early life alterations in the expression of key molecules involved in the aging process in rat offspring. Am J Physiol Regul Integr Comp Physiol. 2008;294(2):R494-R500.

144. Ho SM, Tang WY. Techniques used in studies of epigenome dysregulation due to aberrant DNA methylation: an emphasis on fetal-based adult diseases. Reprod Toxicol. 2007;23(3):267-282.

145. Ptak C, Petronis A. Epigenetics and complex disease: from etiology to new therapeutics. Annu Rev Pharmacol Toxicol. 2008;48:257-276.

146. Catalano PM, Presley L, Minium J, Hauguel-de Mouzon S. Fetuses of obese mothers develop insulin resistance in utero. Diabetes Care. 2009;32(6):1076-1080.
Nutrition and Dietary Supplements

\section{Publish your work in this journal}

Nutrition and Dietary Supplements is an international, peer-reviewed, open access journal focusing on research into nutritional requirements in health and disease, impact on metabolism and the identification and optimal use of dietary strategies and supplements necessary for normal growth and development. The journal welcomes papers covering

\section{Dovepress}

original research, basic science, clinical \& epidemiological studies, reviews and evaluations, guidelines, expert opinion and commentary, case reports and extended reports. The manuscript management system is completely online and includes a very quick and fair peer-review system, which is all easy to use. 